\title{
ESPIRITUALIDADES ARBITRARIAS Y NATURALEZA DESNATURALIZADA
}

\author{
PABLO LÓPEZ LÓPEZ
}

I.E.S. Campos y Torozos

\begin{abstract}
RESUMEN. Términos como «espiritualidad», «naturaleza», «naturalismo» y «religión» se han venido usando con frecuencia de modo engañoso desde el siglo decimoctavo, a partir del sector antirreligioso del lluminismo británico y francés. De hecho, esos términos a veces significan lo contrario de lo que aparentemente expresan. Así pues, necesitamos explorar el significado real de dichos términos, en especial el de «naturalismo». También tenemos que analizar una serie de contradicciones acerca de la comprensión de nociones como «persona» y «religión». Nos proponemos argumentar una nueva fraternidad universal y personal basada en la real naturaleza humana, la real espiritualidad y la real religiosidad.
\end{abstract}

PALABRAS CLAVES: espiritualidad, naturaleza, naturalismo, religión, persona.

\section{Arbitrary spiritualities and denaturalized nature}

ABSTRACT. Terms like «spirituality», «nature», «naturalism» and «religion» have often been used in a deceptive way since the 18th century, starting from the anti-religious sector of the British and French Enlightenment. Indeed, those terms sometimes mean the opposite of what they apparently express. Thus, we need to explore the real meaning of those concepts, especially of the notion of «naturalism». We also have to analyze a number of contradictions regarding the understanding of notions like «person» and «religion». We aim at the reasoning of a new worldwide and personal fraternity based on real human nature, real spirituality and real religiosity.

KEY WORDS: spirituality, nature, naturalism, religion, person.

\section{El USO FALAZ Y ANTINATURALISTA DE «NATURALISMO»}

La filosofía avanza cuestionando a fondo los presupuestos y términos asumidos sin la debida revisión crítica incluso entre filósofos. Al abordar una cuestión delicada, es fundamental cuidar la elección de los términos claves con los que la planteamos. El que unos términos parezcan consagrados por la bibliografía dominante, no obliga a someternos a ellos, sobre todo si trastornan radicalmente nuestra visión y nuestro diálogo. ¿De verdad la expresión «espiritualidad naturalizada» y, en su base, el uso post-ilustrado del concepto "naturalismo» hacen justicia a lo que queremos decir y argumentar con hondura y precisión? ¿No son cartas marcadas al servicio propagandístico de una ideología?

Efectivamente, se trata de algo más que un sofisma aislado o una cuestión erudita. Afrontamos toda una red de intereses encubiertos bajo una denominación eufemística y contradictoria. En esta ideología son contradictorias su pretendida 
denominación de «naturalismo», sus aplicaciones y sus conexiones, como "espiritualidad naturalizada» o "positivismo». Con estas denominaciones dicha ideología se camufla y seduce, ya que expresa con apariencia positiva todo lo contrario de lo que en verdad representa. Envuelve en retórica de "positivismo» su rotundo negativismo, dando a entender que todo discrepante sería reo de «negatividad» o de oposición a la naturaleza. Es justamente todo lo contrario. El falso naturalismo representa la sistemática y radical negación o marginación de la naturaleza humana. Niega toda expresión de iusnaturalismo y de concepción sólida y objetiva de nuestro natural ser, dejándonos a la intemperie de cualquier arbitrariedad, negociada o no. Pero, aunque sea negada o manipulada, nuestra universal naturaleza seguirá existiendo mientras haya seres humanos, y ninguna argumentación o negociación sofística de intereses particulares justificará que se atente contra ella. Por tanto, el pseudo-naturalismo es una pretensión ideológica que justamente debe denominarse "antinaturalismo» $o$ "denaturalismo». No sólo es un pseudo-naturalismo, sino incluso un sistemático y violento rechazo de la naturaleza humana y del orden natural. A él sólo apela, con astucia sofística, por estrategia publicitaria.

Que en parte a veces se haya malinterpretado o manipulado la invocación del orden natural humano, no invalida la necesidad de seguir conociendo y respetando cada vez más lo auténtico de dicho orden. Éste sostiene el sentido de nuestra vida y de nuestra convivencia humanas. Por ejemplo, Aristóteles, imbuido en su cultura, creyó natural lo que nosotros justamente consideramos esclavismo, misoginia y xenofobia. Pero el resto de su interpretación de la naturaleza humana nos sigue enseñando hoy. El iusnaturalismo pagano ya fue corregido y ampliado por el pensamiento cristiano desde su elevada perspectiva sobrenaturalizada. Y puede y debe seguir siendo depurado y desarrollado desde todas las culturas y religiones de hoy y de mañana. En todo caso, nadie caiga en la simpleza de argüir que el iusnaturalismo o la noción misma de «naturaleza humana» responden a una supuesta inclinación «conservadora» o "progresista». La naturaleza humana y su reconocimiento están libres de tales encasillamientos. Nuestra naturaleza tiende a conservarse y, a la vez, es la base de todo progreso y libertad.

En realidad, el camuflaje propagandístico de la ideología denaturalista o antinaturalista se extiende con otros disfraces a otras áreas. Análogamente, el término "positivismo» esconde un desaforado cientificismo en filosofía de la ciencia y una total arbitrariedad iuspositivista en filosofía del derecho. En este campo son variantes «positivistas» el contractualismo y el utilitarismo. Ambos niegan toda posibilidad a la ley natural humana.

Recuérdese siempre que lo que ante todo se niega en todas las variantes del falso naturalismo, es la realidad de la naturaleza humana o su relevancia axiológica. De ahí que el denaturalismo o antinaturalismo antes o después se descubre como liso y llano antihumanismo. Esta ideología tan negativa y corrosiva se presenta a veces con la retórica de un supuesto «humanismo». Pero, si por sistema se niega, minusvalora o manipula la naturaleza humana, se anula lo humano. Y a la progresiva deshumanización sigue el antihumanismo.

A su vez, percibamos que la negación humana de su propia naturaleza es, a fuer de antihumana, nihilista. Hoy el indisimulable antihumanismo ya se presenta sin encubrimiento alguno como "posthumanismo» o «transhumanismo». Éste se reviste de un iluso mesianismo tecnocrático. Recuerda la sofística nietzscheana 
antihumanista y pretenciosamente sobrehumana, por más que ésta sea irracionalista. El irracionalismo no es sobrehumano, sino infrahumano.

Ahora bien, la raíz de toda esta negatividad relativista es el voluntarismo, generalmente emparentado con insolventes concepciones gnósticas o cientificistas. Es la vieja ideología prometeica. Nada tiene que ver con la ciencia ni con su sentido humanista y sapiencial. Empecinada en su propia autoafirmación ilimitada, cortoplacista y de espaldas a la realidad global, la voluntad humana termina por menospreciar la propia realidad humana objetiva, con sus reales posibilidades y limitaciones. Finalmente, por su arbitrariedad irracional de base, el voluntarismo anula la voluntad humana. La aísla y saca de quicio.

En efecto, el término "naturalismo» esgrimido por pensadores antirreligiosos como Hume aparenta tener una noción positiva, la de exaltar una absoluta autonomía de la naturaleza respecto de Dios, prácticamente anulado en la conciencia. Pero, en realidad, lo principal en dicha nomenclatura supuestamente «naturalista» es una rotunda negación, la de lo sobrenatural. Tal énfasis negador de lo sobrenatural y, por extensión, de la entraña religiosa de la razón y del conjunto de la cultura humana, termina revelándose como la total contradicción de lo que pretende ostentar. Hume mismo reduce la naturaleza humana a mera relación de ideas, asociadas por unas leyes bien simplistas. Reduce la antropología a psicología, y ésta, a una versión clausurada y escéptica. Su «Tratado de la naturaleza humana» es un tratado de psicología escéptica. Ni el más rudimentario psicólogo admitiría tal reduccionismo mental.

Así pues, el pretendido "naturalismo» acaba transparentando un férreo antinaturalismo de carácter voluntarista. El antisobrenaturalismo conlleva el antinaturalismo. La guerra contra Dios y su sobrenaturalidad conduce a la guerra del hombre contra el hombre, contra su propia naturaleza libre. No nos dejemos engañar: igual que tantas veces se invoca el nombre de «Dios» para actuar contra Dios, el antinaturalismo se escuda en un fingido naturalismo y un sesgado humanismo para destruir el corazón de lo humano. De hecho, la cultura pseudo-naturalista y voluntarista es, a través de su «iuspositivismo», la implacable negadora de la ley natural y de la naturaleza humana como básico criterio jurídico-moral y político.

Y esta misma cultura positivista o voluntarista, que tanto exhibe una supuesta cientificidad superior, resulta anticientífica. La «naturaleza» que publicitan, es una incoherente naturaleza desnaturalizada, ya sea emanacionista o evolucionista, o bien del todo subjetivista. Asimismo, su espiritualidad viene a quedar paradójicamente desespiritualizada. Resulta un mero espiritualismo arbitrario, que termina sectarizándose o atomizándose en esoterismos comercializados, como los que hoy nos invaden. El humanismo que a veces ostenta, no es sino radical deshumanización. Su exhibicionismo "progresista» esconde un ánimo retrógrado, anclado en convicciones muy parciales y ventajistas: utilitarismos más o menos almibarados. La misma autonomía moral de la que presume, contraponiéndose maniqueamente a una supuesta moral heterónoma de signo religioso, aboca a las mayores heteronomías unilaterales y a esclavitudes sometidas a cualquier ídolo mundano. Incluso su irreligiosidad exhibida encubre su pararreligión autoidolátrica. En suma, todo en este postizo "naturalismo» es falsedad.

Por ello, la llamada "falacia naturalista», denunciada por Hume y Kant, debe considerarse la falacia antinaturalista, en la que ambos incurren. Lo que sostienen 
estos autores, referencias claves del pretendido "naturalismo», es que la naturaleza, el ser mismo de las cosas, nada sirve para fundar u orientar la moral, y, por tanto, la política, el derecho, la economía, la religión, etc. Es decir, niegan la naturaleza como luz para el ejercicio de nuestra libertad. Niegan el conocimiento de la naturaleza y, por ende, su más mínimo sentido orientador. Son completamente antinaturalistas. Son ellos quienes caen en una fatal falacia, pues el mismo «deber ser» que pretenden autofundado, sea en el emotivismo utilitarista o en la pura razón cerrada en sí, no deja de pertenecer al conjunto de los seres o naturalezas. El deber ser es ser. De estos dos autores es, pues, la falacia, la falacia antinaturalista, propia de pensadores antinaturalistas. Su afán antisobrenatural los lleva a negar lo natural. Tras jugarse toda su epistemología a un planteamiento antinatural, subjetivista, antimetafísico y escéptico, ni ellos ni sus análogos pueden ser invocados como referencias de un supuesto "naturalismo». Ellos, como todo su movimiento voluntarista, iluminista y neognóstico, son antinaturalistas y antisobrenaturalistas, es decir, antirreligiosos. El tibio y pragmático deísmo kantiano también distancia de la religión, comunitaria y objetiva.

\section{El VERDADERO NATURALISMO Y SU SUPERACIÓN PERSONALISTA}

Cuestionado el contradictorio y falaz «naturalismo», y dada la escasez de espacio, abrevio también la presentación de lo que, a mi juicio, es el verdadero naturalismo filosófico (obviamente no entramos en el naturalismo artístico-literario). El verdadero naturalismo filosófico o cosmovisivo no es sino el núcleo común de todas las variopintas cosmovisiones o religiones englobadas como "paganismos». En general, éstos no han sido comprendidos precisamente por no captarse su índole naturalista. Por ello, se los despacha muchas veces con indiscriminado desprecio, ignorando sus relativos valores. En comparación con el desenfrenado antinaturalismo contemporáneo hoy es fácil resaltarlos. En cualquier naturalismo o paganismo siempre ha habido y perdura cierto respeto por lo natural, un notable comunitarismo y un hondo sentido de transcendencia. Sus deficiencias y confusiones son claras, como vamos a ver, y hace dos mil años que resulta anacrónico.

El específico naturalismo de los paganos nace de asumir como dato inmediato y universal que todo lo existente es natural. Es decir, ni siquiera para lo divino se concibe lo sobrenatural. Lo divino y su superioridad ontológica les resultan generalmente incuestionables, pues la divinidad (o cierto absoluto transcendente) representa la clave del orden y del sentido de todo lo real, de toda la naturaleza, a la que pertenece. Insisto en que, a diferencia del antisobrenaturalismo antinatural, el auténtico naturalismo no niega ni afirma lo sobrenatural, pues ni alcanza a planteárselo, pese a magnificar y entronizar lo sacro y divino. Esto se ensalza como sobrehumano, pero no como sobrenatural. No obstante, desde su sentido transcendente la religiosidad pagana apunta a lo sobrenatural, aunque no lo termine de distinguir.

Un problema de los naturalismos es su fuerte tendencia a la confusión sincrética entre religiones, y entre lo divino, lo humano y hasta lo cosaico. Su antropología y sus valores son pre-personalistas. Esto sigue siendo patente en los naturalismos más vivos: los hinduismos y budismos. 
Unido a todo ello, el naturalismo se caracteriza también por su circularismo o visión circular, habitualmente decadentista (cf. mito de las edades), sobre el conjunto de la historia y de la vida humanas. Tal circularismo lastra enormemente una límpida noción y vivencia de libertad personal y social.

$\mathrm{Y}$, dentro de su fundamental confusionismo cosmovisivo y antropológico, otro de sus rasgos principales es la indistinción básica entre poder político y poder religioso. Esto se manifiesta en el continuo y sistemático cruce de atribuciones políticas y religiosas. Ejemplos preclaros de ello son figuras como las de los faraones o los emperadores romanos, sujetos divinizados que concentraban todo el poder político, sin que por su practicidad faltaran grupos específicos de sacerdotes o gobernadores. Tal fusión o confusión sistemática de lo político-jurídico y lo religioso perdura también en el islam. Éste se inspira en parte en el judeocristianismo (el monoteísmo transcendente y el profetismo), y en parte sigue criterios naturalistas o paganos (el creer que se nace musulmán, la sacralización de la ley y de la autoridad políticas).

Sólo el Evangelio ha introducido una clara distinción entre los órdenes politico y religioso, gracias a su avanzada distinción armonizadora entre lo natural y lo sobrenatural: "Dad al César lo que es del César, y a Dios lo que es de Dios», en palabras del maestro Jesús de Nazaret. La misma diferenciación eclesiológica entre la jerarquía sacerdotal, con sus funciones bien establecidas, y la jerarquía civil o laica, también con sus funciones propias, avala tal principio. La misma Iglesia crea y desarrolla la noción de «laicado» o «laicidad». Ésta nada tiene que ver con sus derivaciones erráticas y beligerantes de tipo laicista y secularista, que también suelen parapetarse en la retórica de un falso naturalismo. Como otros preceptos cristianos, el de la justa distinción entre poder civil y autoridad eclesial no siempre se ha llevado cabalmente a la práctica, pero su directriz ha ido marcando el curso de las culturas influidas o desarrolladas por los cristianos.

Otra de las grandes aportaciones de la cultura cristiana a la humanidad es la nítida afirmación y el encumbramiento de la realidad personal y de su dignidad. El prepersonalismo naturalista o pagano ha sido superado por el personalismo cristiano. También el colosal descubrimiento antropológico y moral de la persona y de su plena dignidad remite a la nítida y armónica distinción cristiana entre lo natural y lo sobrenatural. Desde ella, el cristiano contempla su dignificante analogía espiritual y personal con la sobrenaturalidad de Dios, uno en esencia e íntimamente tripersonal. No por ello el cristiano olvida su propia condición natural y humana. En las mejores versiones del naturalismo o paganismo aletea cierto humanismo, que permite vislumbrar destellos de una prefiguración de la conciencia personal. Recordemos a Cicerón y a Séneca. Tal humanismo se eleva en la exaltación personalizadora, de inspiración trinitaria y encarnacional. Pero se hunde en la despersonalización antinaturalista.

Los primeros concilios ecuménicos y la Patrística perfilan el descubrimiento de la grandeza incomparable del ser personal, insigne por su espiritualidad. Desde entonces, queda claro que somos espirituales, porque somos personas, así como que somos personas, porque somos espirituales. Somos espirituales y no de cualquier manera, sino a imagen y semejanza de Dios, tan sumamente personal. $\mathrm{La}$ persona es el espíritu en tanto que perfilado como ser uno y único, libre, intimamente comunicativo y de valor final. A su vez, cabe entender el espíritu como el ser capaz. 
de inteligencia y voluntad abiertas a lo universal. Tal capacidad puede hallarse más o menos desarrollada o activa.

El personalismo, aun siendo un elevado humanismo de origen cristiano o eclesial, posee un impacto dignificador para todas las culturas. El personalismo supera la rudeza de los naturalismos, porque reafirma depuradamente la naturaleza humana en su gran entorno ecológico, y porque abre a lo sobrenatural éntimo de lo divino. El personalismo cristiano es, además, universalista, pues defiende la dignidad personal para todos los seres humanos, sin discriminación alguna.

El mismo kerigma cristiano ofrece en su espiritualidad la mejor sintesis personalista entre la divina sobrenaturalidad y la humana naturaleza. En Cristo una naturaleza humana ya ha sido elevada a la categoría de persona divina, cual preludio de la elevación de las personas humanas a la condición de naturalezas divinizadas por adopción filial. En Cristo, Dios, todo Él sobrenatural, se ha naturalizado. Se ha hecho naturaleza humana. Su eternidad se ha secularizado, entrando, con todas las consecuencias, en el «saeculum» u orden temporal. Y sin perder su condición divina. Todo el valor de lo natural ya está perfectamente contenido en Él, sin excesos ni parcialidades sacralistas o naturalistas.

Se dirá que es cuestión de fe. Pero es una fe o confianza sumamente razonable y sapiencial, bella y dignificadora, incomparable. No hay filosofías y teologías tan amplia y profundamente desarrolladas y sostenidas como las cristiano-católicas. La perfección de tal modelo de vida personal, que tantas vidas transforma y eleva, se ofrece a quien quiera acercarse a su misterio de luz. En todo caso, ¿qué gran sistema de ideas alternativo no se apoya, en última instancia, en algún tipo de fe?

\section{LA NATURALEZA DESNATURALIZADA Y LA DESPERSONALIZACIÓN DE LA PERSONA}

Es importante, preliminar y necesario aclarar crítica y constructivamente los términos claves, como hemos hecho. Mas no basta. El problema que afrontamos, va mucho más allá de unos términos. El problema reside no sólo en la manipulación de la noción de "naturalismo» y de su supuesto "positivismo», en la marginación de la idea de "espíritu», y en la incomprensión de lo personal. Ciertamente, se manipula de continuo la noción de "naturaleza», sobre todo aplicada a la humanidad. Se hace un uso ideológico y anticientífico de la propia ciencia, so capa de «positivismo». Se habla mucho y vagamente de «espiritualidad», pero se margina el espíritu, el alma y el compromiso serio, perfilado y comunitario de la religión. Se sigue apelando al valor de la persona, pero desde una versión desespiritualizada, desalmada y fuertemente discriminativa, sobre todo en el terreno bioético. En fin, se trata de toda una serie de desorientaciones básicas de graves consecuencias prácticas. Por ello, este crucial problema de toda nuestra cultura globalizada es no sólo teórico. El problema también se materializa masivamente en la desnaturalización de la naturaleza humana y en la misma despersonalización de tantas personas. Expongámoslo de modo sucinto.

Negar o confundir la naturaleza humana, que justo se distingue por su racionalidad y conciencia, no queda en mero error teórico o conceptual. Afecta muy negativamente a la misma entraña humana en su día a día. Al negar nuestra naturaleza, 
nos negamos a nosotros mismos. Tal contradicción nos desvertebra, desarraiga y corroe por dentro, tanto en lo individual como en lo social. Por no hablar de lo destructiva que resulta en las diversas manifestaciones externas de la cultura.

Para apartarse del criterio de lo natural, suele pretextarse la salvaguarda de la libertad, de la conciencia, e incluso de la democracia. Pero desnaturalizar la libertad, la conciencia y la democracia, alejándolas de sus requisitos o condiciones naturales, las desvirtúa y adultera. Desnaturalizarnos es deshumanizarnos. Nuestra naturaleza no es un mecanicismo del cual debamos zafarnos, sino la condición de posibilidad de nuestro ser libres.

La libertad no es un mero derecho a decidir arbitrariamente cualquier cosa, sino la capacidad de elegir el bien. Nuestra libertad exige responsabilidad, esfuerzo y autosuperación en pro del verdadero bien. No hay bien humano que se oponga a la naturaleza humana, pues nuestra misma naturaleza es nuestro primer bien. Ni cabe una contradicción entre naturaleza y libertad humanas, ya que lo peculiar de la naturaleza humana es que es la naturaleza libre. Por ser naturaleza, nace con unas determinadas características y limitaciones universales. Por su libertad, se abre a un sinfín de potencialidades creativas y personalizables. Por su naturaleza el humano es finito. Pero por su libertad esta finitud se abre al infinito. Podríamos definir la naturaleza humana como la naturaleza abierta al infinito, intelectual y volitivamente, con honda espiritualidad. Desde su inmanencia está paradójicamente abierta a la más elevada transcendencia.

La subjetividad de la conciencia madura al asumir y asimilar personalizadamente la objetividad de lo real. Tal asimilación empieza por la objetividad de nuestra naturaleza humana, por sí misma abierta a la transcendencia. Nuestra libertad no estriba en manipularla, negarla o darla por superada, sino en cuidarla y cultivarla creativamente. Tal es nuestro bien objetivo, que se puede desarrollar con una legítima pluralidad cultural y personal. Precisamente nuestra naturaleza espiritual nos dota de subjetividad, de íntima conciencia única e irrepetible. Es un objetivo deber universal el cuidado de nuestra recta conciencia y, desde ella, de nuestro entorno y relaciones personales.

La democracia es mucho más rica que un mero procedimentalismo amoral, sin valores. Pivota sobre el respeto a los verdaderos valores humanos y culturales. $\mathrm{La}$ democracia es la libertad ampliamente compartida. Por ello, es también elegir el bien, por parte de un pueblo. Elegir el bien hace poderoso a un pueblo. Elegir el mal lo empobrece y esclaviza.

La consecuencia práctica de nuestra desnaturalización y su agravamiento se verifican, por ejemplo: en la pérdida sistemática de respeto a la vida y a la dignidad humanas, sobre todo a la de los más débiles (en gestación, con graves enfermedades o discapacidades, etc.); en la destrucción o desestructuración masivas de innumerables familias; en el adocenamiento cultural, pedagógico y académico; en el aumento del suicidio, de diversas adicciones, de depresiones, ansiedades y otros trastornos mentales y conductuales ; y en el insaciable secularismo laicista.

Se reconocen las actuales crisis políticas, las económicas, las medioambientales $\mathrm{y}$, aunque con diversas interpretaciones, hasta las morales. Pero debe reconocerse también el fondo global de la crisis actual: una inusitada crisis antropológica y teológica. Hoy un sinnúmero de seres humanos, acaso muy informados e instruidos tecnológica y profesionalmente, se halla perdido ante la vital pregunta de qué es 
lo humano, de cuál es su naturaleza, y del porqué de su dignidad. Hoy se tiende a confundir lo humano y lo meramente animal, lo humano y la máquina, y lo humano y lo divino. Demasiados seres humanos se creen reducidos a simples animales, se comportan como máquinas o se someten a ellas, y se endiosan o absolutizan a sí mismos.

Desnaturalizada nuestra humanidad, pierde sus perfiles la propia identidad personal. Las personas en nuestra cultura tan desorientada quedan muchas veces incomunicadas, masificadas y consumidas por su consumismo o por la pura miseria. Los mismos populismos, que engatusan a unos y a otros diciéndoles irresponsablemente lo que quieren oír, hunden los pueblos que los entregan su confianza. Parasitan la parte no personalizada o cultivada de las personas o espíritus.

\section{LAS ESPIRITUALIDADES DESESPIRITUALIZADAS Y LAS RELIGIOSIDADES IRRELIGIOSAS}

La persona humana es no sólo espíritu. Es espíritu somatizado. Es cuerpo espiritual. Todo nuestro ser es psicosomático. Pero, en cuanto persona, el humano se distingue por su espíritu, cuyo desarrollo intimo es su espiritualidad. Todo esto suele soslayarse. Son legión los que hablan durante horas y hasta años sobre la persona, pero sin reconocer su entraña espiritual. Asimismo, hablan y enseñan sobre "espiritualidades», pero sorprendentemente les sobra la noción de «espíritu», siendo obvio que no cabe espiritualidad sin espíritu. Incluso se pretende dar lecciones sobre espiritualidad desde posiciones netamente materialistas. ¿Cómo distinguirnos y valorarnos como personas frente a los simples animales y la pura materia, si no reconocemos paladinamente nuestra esencia espiritual? El propio autoconocimiento íntimo y la ponderación de nuestras capacidades universalistas de conocimiento y voluntad sostienen la conciencia aún mayoritaria de que somos espíritu y de que lo hemos de cultivar.

Así pues, no extraña que, desnaturalizadas y despersonalizadas tantas personas humanas y tantas culturas, muchas espiritualidades proclamadas queden enclenques y sirvan más bien de anestesia o placebo ante tanto vacio interior, ante tanto sinsentido existencial. Resulta particularmente contradictorio, como he indicado, que se pretendan construir espiritualidades desde los más recalcitrantes materialismos, sean ideologías como la marxista o estilos de vida frenéticamente consumistas. No hay que incurrir en espiritualismo alguno para cultivar una sana y equilibrada espiritualidad. Hay que integrar siempre nuestra noble somaticidad. Pero es antinómico pretender una espiritualidad materialista, que sería como una espiritualidad antiespiritual.

Naturalmente, hasta el pensador más materialista no deja de ser humano y por tanto es espiritual, por más que le pese. De ahí que de alguna forma desarrolla una espiritualidad. Pero no podrá tomar conciencia de ello con coherencia. Así, no podrá madurar en espíritu. ¿Cómo saludar tal jibarización materialista de la conciencia y del mismo espíritu?. Igual que el cuerpo puede deformarse, el espíritu puede envilecerse.

Además, empobrece y desorienta al alma el reciente énfasis en una multitud divergente de supuestas espiritualidades acomodaticias y arbitrarias como 
subterfugio para eludir la responsabilidad de la espiritualidad religiosa. Podemos estimar esta tímida apertura a una conciencia espiritual, aunque sea desde un contradictorio materialismo y un negativo ateísmo (todo ateísmo es negación, una negación absoluta). Pero, a la larga, si se estanca como espiritualidad irreligiosa, termina siendo una espiritualidad desespiritualizada, por su intrínseca pobreza y alienación nihilistas. El desequilibrio está servido hacia un espiritualismo desencarnado y descomprometido, sobre todo de tipo gnóstico o esotérico, o bien hacia un grosero materialismo hedonista y utilitarista. Toda esa irreligión se absolutiza o idolatra, generando otra honda contradicción básica: la de las «religiones» o pseudo-religiones irreligiosas. Así, tantas veces se ha pensado en el marxismo como «religión atea», o en el capitalismo entendido como idolatría del dinero.

Las heterogéneas y hueras "espiritualidades» del pseudo-naturalismo voluntarista se caracterizan por su gran arbitrariedad, su relativismo y su debilidad racional, ya sean de corte desequilibradamente espiritualista o de corte contradictoriamente materialista. Ni son naturales, pues más bien son antinaturales y desnaturalizan; ni merecen el título de «espiritualidades», pues arrojan a la arbitrariedad y a la desespiritualización materialista, hedonista o egocéntrica. Más que falsas religiones, funcionan como pseudorreligiones a la carta, ya sean descomprometidas o excesivamente beligerantes. No llegan a constituirse como religiones.

Frente a los funestos desequilibrios materialistas y espiritualistas, caracterizados por sus monismos o dualismos respectivos, la antropología cristiana ofrece una síntesis ponderada, armónica y gozosa de materia y espíritu. Reconoce su distinción (frente a los monismos materialistas), pero equipara su importancia y los integra y compenetra (frente a los dualismos). Ninguna otra religión o humanismo como el del Evangelio muestra una exaltación simultánea tanto del espíritu como del cuerpo. Destina ambos a la máxima gloria celeste, por lo que los protege y promueve amorosamente durante su periplo temporal. El Evangelio es, por antonomasia, la religión del cuerpo, la de Dios encarnado en un cuerpo que se entrega por todos los hombres, y resucita corporalmente en pro de la resurrección de todos los que le acojan. Y el Evangelio es también el humanismo del espíritu, pues exalta el alma humana hasta su renacer en la santidad de la filiación divina. El Evangelio no es ni materialista ni espiritualista, sino la afirmación más elevada del simultáneo valor del cuerpo y del alma compenetrados.

Tantas espiritualidades quedan desespiritualizadas por su materialismo o su falta de humanismo. Tantas religiosidades resultan irreligiosas por su secularismo o mundanización, por su fanatización, o por su espiritualismo desencarnado. Por desgracia, nada de esto es extraño, habida cuenta de la fácil deshumanización de tantos seres humanos. Ante todo ello, descubramos desde nuestros más íntimos y nobles anhelos humanos y desde el conocimiento experiencial más profundo la verdad espiritual y religiosa del Evangelio vivido en la autenticidad de los santos.

No madura la religión sin espiritualidad, ni la espiritualidad sin religión. Sin espiritualidad la religión queda en puro ritualismo externo. Se anula. Y tampoco crece la espiritualidad sin religión, como ahora se pretende, pues se degenera en algún arbitrario o caprichoso espiritualismo de autoconsumo, desequilibrado humana y teológicamente. 
5. Llamada A LA MILITANCIA DEL PENSAMIENTO, DE LA TRANSCENDENCIA Y DE LA FRATERNIDAD

Más allá de conclusiones teóricas, ya expuestas, finalicemos con un llamamiento práctico. Convoquemos día a día a pensar y construir con fundamento, enjundia, coherencia y valentía una renovada fraternidad universal, humanista, espiritual y religiosa, contando de partida con un amplio pluralismo religioso e incluso con posturas irreligiosas. La única condición para todos es compartir un cierto humanismo básico, el de nuestra naturaleza libre y personal, que parte de respetar el derecho objetivo a la vida de cada persona humana.

Frente al pensar inmanentista, materialista, espiritualista, unilateral o ventajista, recobremos y relancemos un pensar y un obrar transcendentes, altamente espirituales, encarnados, globales y fraternos. Son valores muy genéricos. Pero, en su autenticidad, son los que necesitamos para reavivar en esta humanidad de nuevo milenio unas espiritualidades bien racionales y religiosas. Es lo que nuestra propia naturaleza demanda y premia.

I.E.S. Campos y Torozos

PABlo López López

pablosamba@hotmail.com

[Artículo aprobado para publicación en diciembre de 2016] 